\title{
NUEVAS CITAS Y AMPLIACIÓN DE LA DISTRIBUCIÓN CONOCIDA DE ROPALÓCEROS EN LA COMUNIDAD VALENCIANA Y PROVINCIA DE TERUEL
}

\author{
S. Montagud* y J. A. García-Alamá*
}

\begin{abstract}
RESUMEN
Se aporta información sobre 18 especies de ropalóceros presentes en la Comunidad Valenciana y provincia de Teruel. Algunas de estas especies se dan a conocer por vez primera de esta región, como es el caso de Danaus plexippus (Linnaeus, 1758), Erebia meolans (de Prunner, 1798), Polyommatus (Meleageria) daphnis (Denis \& Schiffermüller, 1775), Laeosopis roboris (Esper, 1789), Nordmannia acaciae (Fabricius, 1787) y Plebeius hespericus (Rambur, 1839). Para el resto se amplía considerablemente su distribución conocida y/o se acompaña de algunos comentarios de interés sobre su biología: Euchloe belemia (Esper, 1800), Pieris mannii (Mayer, 1851), Zegris eupheme (Esper, 1804), Colotis evagore (Klug, 1829), Aporia crataegi (Linnaeus 1758), Erebia epistygne (Hübner, 1819), Melitaea cinxia (Linnaeus, 1758), Libythea celtis (Laicharting, 1782), Glaucopsyche (Iolana) iolas (Ochsenheimer, 1816), Scolitantides orion (Pallas, 1771), Neozephyrus quercus (Linnaeus, 1758) y Plebeius (Aricia) morronensis Ribbe, 1910.
\end{abstract}

Palabras clave: Lepidoptera, Rhopalocera, Pieridae, Danaidae, Nymphalidae, Lycaenidae, Comunidad Valenciana, Teruel, España.

\section{ABSTRACT \\ New records and increase of the known distribution of Rhopalocera species in the Comunidad Valenciana and Teruel province}

The authors summarize data for 18 species of Rhopalocera to complete knowledge of their distribution and biology in Comunidad Valenciana and Teruel province. These species have been selected for two reasons: 1) Danaus plexippus (Linnaeus, 1758), Erebia meolans (de Prunner, 1798), Polyommatus (Meleageria) daphnis (Denis \& Schiffermüller, 1775), Laeosopis roboris (Esper, 1789), Nordmannia acaciae (Fabricius, 1787) and Plebeius hespericus (Rambur, 1839) are new records for Comunidad Valenciana and 2) Euchloe belemia (Esper, 1800), Pieris mannii (Mayer, 1851), Zegris eupheme (Esper, 1804), Colotis evagore (Klug, 1829), Aporia crataegi (Linnaeus 1758), Erebia epistygne (Hübner, 1819), Melitaea cinxia (Linnaeus, 1758), Libythea celtis (Laicharting, 1782), Glaucopsyche (Iolana) iolas (Ochsenheimer, 1816), Scolitantides orion (Pallas, 1771), Neozephyrus quercus (Linnaeus, 1758) and Plebeius (Aricia) morronensis Ribbe, 1910, for these species, known distribution is considerably extended and interesting data about their biology are provided.

Key words: Lepidoptera, Rhopalocera, Pieridae, Danaidae, Nymphalidae, Lycaenidae, Valencian Community, Teruel, Spain.

* Museu Valencià d'Història Natural. Fundación Entomológica Torres Sala. Paseo de la Pechina 15, 46008 Valencia ESPAÑA. E-mails: sergio.montagud@uv.es, alamacontrabaix@hotmail.com 


\section{Introducción}

El Museu Valencià d'Història Natural (Fundación Entomológica Torres Sala) está realizando actualmente un proyecto para la catalogación y registro de los ropalóceros valencianos. Dicho proyecto, financiado por la Dirección General de Gestión del Medio Natural, Consellería de Territori i Habitatge de la Generalitat Valenciana, tiene como fin el dar a conocer, en una publicación en forma de manual o guía de campo, la fauna de ropalóceros presentes en la Comunidad Valenciana. En estos últimos meses, los autores del presente trabajo hemos recopilado datos procedentes tanto de referencias bibliográficas, de revisión de material depositado en colecciones públicas y privadas, así como de campañas de muestreo efectuadas para tal fin. Durante esta labor se nos han planteado algunos aspectos relativos al interés de ciertas citas, bien por tratarse de localizaciones alejadas de la distribución conocida de la especie, bien por diferentes cuestiones que merecen especial discusión y que no tienen cabida en aquella obra. Por todo ello, hemos decido reunir y dar a conocer estos datos en este trabajo.

Los ropalóceros s. 1., entre los que reconocemos a nivel paleártico las superfamilias Papilionoidea y Hesperioidea, han sido objeto de varios trabajos dentro de los límites de la Comunidad Valenciana. Los primeros registros se remontan a principios del siglo XX y proceden de obras generales como las de Boscá (1916) y Pardo (1920); aunque como bien apunta Agenjo (1959), estas citas han de referirse con cuidado, pues los mencionados autores no eran especialistas en el grupo y sus listas de especies, además de datos poco precisos, pudieran albergar errores de determinación. Este mismo autor, Agenjo, aportará desde 1963 hasta 1972 muchos registros en referencia no sólo a ropalóceros, sino a lepidópteros en general con presencia en la Comunidad Valenciana, especialmente a lo largo de publicaciones muy puntuales en la "Sección de Capturas" de la revista Graellsia. También dedicó un trabajo específico a la lepidopterofauna valenciana, que presentó en esta misma revista y en donde, aparte de una exposición histórica sobre el estudio de esta materia en dicha región, insiste en el poco conocimiento de que disponemos sobre sus especies y el potencial que debe albergar debido a su diversidad geográfica (Agenjo, 1959). Pocos años más tarde se publica el Catálogo de la Colección Entomológica Torres Sala (Torres Sala, 1962), un inventario en el que figuran cerca de 50 especies de procedencia valenciana, eso sí, restringidas sólo a unas pocas localidades de estudio. A partir de este año comienza a adivinarse un impulso en el estudio de la lepidopterofauna de esta Comunidad, sin duda ligado al desarrollo a nivel nacional de la sociedad SHILAP y la labor de sus socios, que dan lugar a varias aportaciones de nivel general y de compendio (Blat Beltrán, 1982; Calle, 1983). Merece destacarse entre ellas la importante obra "Lepidópteros ropalóceros. Cuadernos de la fauna alicantina" (Robert et al., 1983), obra ejecutada con metódica y precisa labor de muestreo de campo y que aún hoy continúa siendo un referente para aquella provincia.

A esta línea se sumaron otros autores que acometieron aportaciones de carácter local, casi siempre para señalar especies de amplia repartición en listados faunísticos de localidades singulares, como reservas y parajes naturales (Huertas, 1974; Font Bustos, 1978, 1984; Baixeras, 1983; Muñoz, 1983; Tormo, 1983, 1985; Docavo et al., 1987; Bellavista et al., 1989; Hecq, 1991) y que han permitido ampliar el conocimiento sobre la distribución de estos insectos en la Comunidad.

Actualmente, el grupo de la Universidad Autónoma de Madrid ha emprendido una ingente labor de recopilación de registros de mariposas ibéricas, trabajo que ha quedado plasmado en forma de atlas recientemente publicado (García-Barros et al., 2004). Esta obra ha permitido poner en manos de los interesados un catálogo corológico puesto al día, que resulta sumamente útil para emprender trabajos como éste y predisponer a entomólogos y aficionados para aportar sus registros y así completar nuestro conocimiento sobre la distribución actual de las especies ibéricas. Con todo, los autores de este atlas ya señalan la falta de registros existente en ciertas zonas de la Península debido, en la mayoría de los casos, a una carencia de muestreos (García-Barros et al., 1999). Entre estas zonas destaca especialmente la parte interior de la provincia de Valencia y casi la totalidad de Castellón. Algunas de las especies que a continuación se tratan han sido seleccionadas por representar las primeras citas en la Comunidad Valenciana de las que se tiene noticia y vienen a completar en parte este vacío. Otras, bien extienden su área de distribución conocida o bien se incluyen por aportar datos de interés sobre su biología.

\section{Metodología}

Los nuevos datos presentados en este trabajo provienen de la revisión de colecciones cuyos registros permanecían inéditos, así como de campa- 
ñas de recolección actuales efectuadas dentro del proyecto de catalogación de ropalóceros de la Comunidad Valenciana que está llevando a cabo la Fundación Entomológica Torres Sala. Estos muestreos en el campo se han intensificado especialmente en aquellas zonas donde se disponía de pocos o ningún dato de distribución de especies, siguiendo a García-Barros et al. (2004). Los mapas de distribución se han generado con el programa ArcMap, empleando una rejilla de cuadrículas UTM de $10 \mathrm{~km}$ de lado. Todos ellos reflejan la distribución de especies de ropalóceros en la Comunidad Valenciana. Con triángulos se representan las citas bibliográficas; con puntos, los registros nuevos.

Respecto a la nomenclatura de las especies y debido a los importantes cambios que ha sufrido recientemente, hemos creído oportuno emplear la utilizada en el proyecto Fauna Europaea (www.faunaeur.org), proyecto en el que han participado especialistas de prestigio y que por su condición de soporte informático, se encuentra en continua actualización.

COLECCIONES CONSULTADAS Y ABREVIATURAS:

Colecciones públicas:

ICBiBE: Colección de Entomología de l'Institut Cavanilles de Biodiversitat i Biología Evolutiva. Universitat de València.

Colecciones privadas:

FETS_CEGN: Colección de Entomología General, Fundación Entomológica Torres Sala.

CSM: Colección S. Montagud.

CGA: Colección J.A. García -Alamá.

\section{Resultados y discusión}

\section{Familia Pieridae}

\section{Euchloe belemia (Esper, 1800)}

MATERIAL ESTUDIADO: VALENCIA: La Fardeta, Llíria, 30SXK90; 107, 11-IV-1987 (J.A. García Alamá). CGA.

Especie bien extendida en las localidades meridionales de la Comunidad Valenciana, donde mantiene importantes poblaciones en la provincia de Alicante, siendo incluso en algunos puntos muy frecuente. Esta situación se presenta también en el resto de la Península; muy extendida en el sur y con citas aisladas en muchas provincias septentrionales, algunas de ellas antiguas y sin reciente comprobación. Es clásica la referida por Graells en 1852 de Aranjuez (Agenjo, 1969) y que durante mucho tiempo (lo que ha ocurrido ya varias veces con este autor) se mantuvo como dudosa; posteriormente se recapturó y comprobó la estabilidad de sus poblaciones.

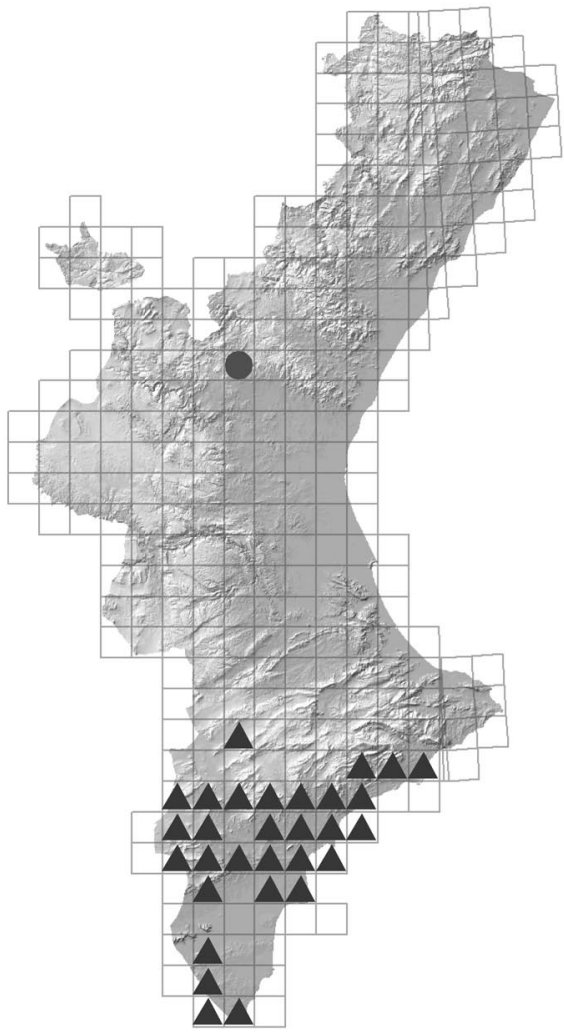

Fig. 1.-Euchloe belemia.

Es pues una especie eminentemente meridional cuyos registros en el centro peninsular han sido considerados siempre como excepcionales. Así, la cita que refieren Zapater y Korb (1883), en su famoso catálogo, es comunicada como "un solo ejemplar, autentico, entre Teruel y Albarracín ". En la Comunidad Valenciana esta especie no había sido registrada al norte de la provincia de Alicante. El ejemplar capturado en Llíria es un macho de la $2^{\circ}$ generación La zona donde se efectuó la captura ha sido frecuentemente visitada y no ha vuelto a observarse ningún ejemplar, por lo que consideramos improbable el establecimiento de una población estable. No se han consignado hábitos migratorios para la especie, sin embargo estos ejemplares aislados, por lo frecuente de su aparición, deben estar relacionados con alguna actividad "divagante" propia de la especie y no sólo responder como casos excepcionales de traslado o deriva de ejemplares.

En la literatura se refieren como plantas nutricias, crucíferas de los géneros Diplotaxis, Biscutella y Sisymbrium. Estas plantas se encuentran muy extendidas y particularmente Sisymbrium officinale podemos encontrarla con frecuencia en los márgenes de caminos 
y terrenos de cultivo. La ausencia de la especie por lo tanto no puede justificarse por falta de plantas nutricias.

\section{Zegris eupheme (Esper, 1804)}

MATERIAL ESTUDIADO: VALENCIA: Baños de Fuentepodrida, Requena, 30SXJ45; 1 \% 29-IV-2001 (S Montagud). CSM; Los Lavajos, Sinarcas, 30SXK50; $10^{7}$, 27IV-2003 (S. Montagud). CSM. Fuentejórgola, Domeño, 30SXJ79; una larva sobre Hirschfeldia incana; V-2004 (S. Montagud); Fuente de la Canaleta, Andilla, 30SXK80; 16-IV2006 (un ejemplar en vuelo, S. Montagud); El Pontón, Requena, 30SXJ57; 107, 30-IV-2006 (S. Montagud) FETS_CEGN; Rio Cabriel, Venta del Moro, 30SXJ35; 30-IV2006 (un ejemplar en vuelo, S. Montagud).

Señalada por primera vez para la Comunidad Valenciana de Busot, provincia de Alicante (Agenjo, 1952). Extendida y a veces abundante en esta provincia (Robert et al., 1983), pero aún no registrada en Valencia y Castellón. Se trata de una especie de hábitos claramente esteparios y muy relegada a zonas de trigales y cultivos cerealistas. Las capturas cuyas citas aportamos se realizaron en estas condiciones. Es interesante el hecho de que, pese a que el alimento de las larvas se restringe a ciertas especies de crucíferas, estas son de amplia distribución y en modo alguno contribuyen a lo confinado de su hábitat. Deben existir otros factores, probablemente una serie de condiciones ambientales necesarias durante el desarrollo en los estados preimaginales, que limitan a esta especie a dichos hábitats. Fuera de la Península su distribución abarca, de forma fragmentaria, zonas esteparias similares del Norte de África, Rusia y Asia Central. Sus plantas nutricias las constituyen crucíferas silvestres de los géneros Hirschfeldia (sobre las que ha sido encontrada una larva en la provincia de Valencia), Sisymbrium, Biscutella e Isatis, muchas de ellas consideradas como malas hierbas que crecen en las lindes y bordes de estos campos de labor.

\section{Pieris mannii (Mayer, 1851)}

MATERIAL ESTUDIADO: VALENCIA: Embalse de Embarcadero, Cofrentes, 30SXJ74; 30 $0^{\pi}, 29-\mathrm{V}-2005$ (S. Montagud \& M.A. Ibáñez Orrico). CSM. Muela de Cortes, Cortes de Pallás, 30SXJ74; 10", 23-III-2002 (S. Montagud). CSM. El Moragete, Jalance, 30SXJ64; 1 ㅇ, 6-VI-2004 (S.

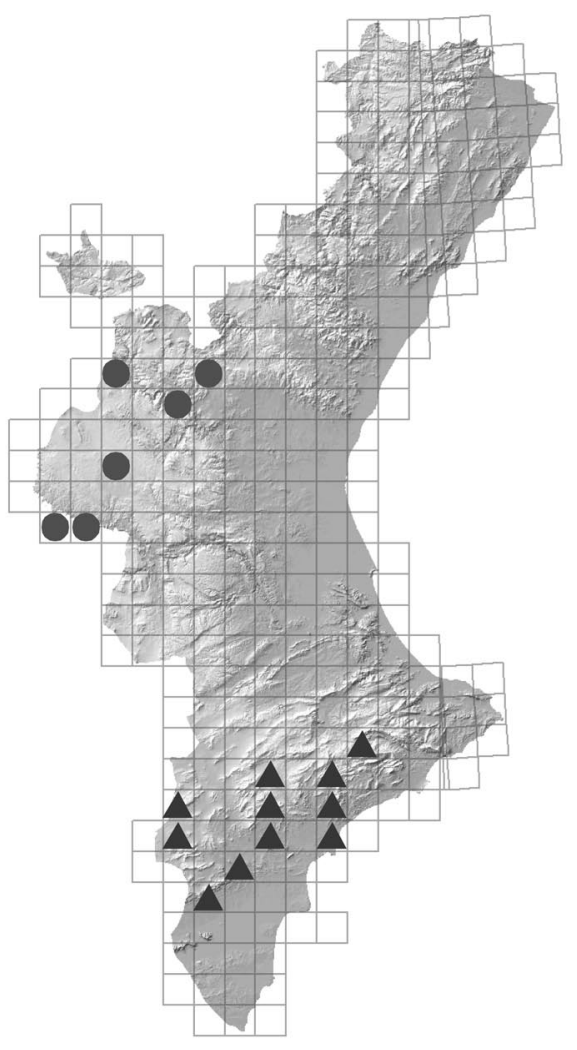

Fig. 2.-Zegris eupheme.

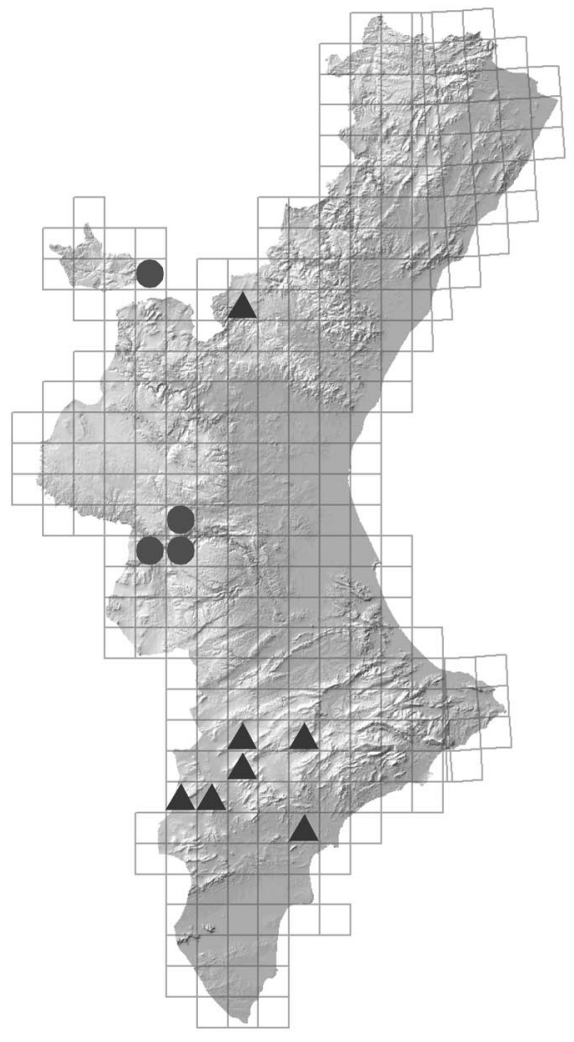

Fig. 3.- Pieris mannii. 
Montagud, M. Ibáñez-Orrico \& A. Pérez-Onteniente). CSM. Casas de Herrero, Cortes de Pallás, 30SXJ75; $20^{7} \sigma^{7}$, 23-III2002 (S. Montagud). CSM. Cortes de Pallás, 30SXJ75; 10", 24-III-2005 (J.A. García-Alamá). CGA.

TERUEL: Fuente La Cederilla, Camarena de la Sierra, 30TXK63, 10", 4-VIII-2001 (S. Montagud). CSM.

Considerada tradicionalmente como una especie rara y localizada. En la Comunidad Valenciana se conocía su presencia en las provincias de Alicante y Castellón. De esta última la refiere Agenjo en su nota 316 de la "Sección de Capturas" de la revista Graellsia (Agenjo, 1978); sin embargo, la localidad está equivocada; el paraje conocido como La Almarja o Masía de la Almarja (30XK8721) no se encuentra en el término municipal de Bejís, sino en el de El Toro. Hemos hallado esta especie en cuatro localidades de la provincia de Valencia, siendo en todas ellas abundante al igual que indican otros autores acerca de las poblaciones alicantinas (Robert et al., 1983). Este insecto parece restringirse a zonas de pinar denso, generalmente Pinus halepensis en las cotas medias y bajas, con abundante sotobosque y accidentes geográficos que propician la aparición de barrancos con una humedad relativa mayor de lo normal; es frecuente que acuda a los "bebederos". En estos parajes puede convertirse en la especie más numerosa del género superando incluso a la pertinaz Pieris rapae. Sus plantas nutricias pertenecen al género Iberis, asociado a matorrales calcícolas, que crecen en claros del bosque y roquedos. Es muy probable que se amplíe su distribución en las provincias de Valencia y Castellón, pues conociendo su hábitat, fácilmente es detectada en cuanto se reconoce el terreno. Sin embargo esta singularidad hace más problemática su conservación. La frecuencia de los incendios forestales que afectan a esta comunidad y que se ceban con este tipo de pinares, acaba destruyendo el entorno apropiado para la especie. Pese a que tras los incendios se recupera parte de la vegetación y la biodiversidad de lepidópteros puede incluso incrementarse (tanto con especies singulares como oportunistas), el hábitat no resulta apropiado para esta especie que no tiene oportunidad de reaparecer hasta la consolidación del pinar, muchos años después. Algo similar ha ocurrido con las poblaciones valencianas de Euchloe tagis (Hübner, 1804), asentadas en los municipios de Benagéber, Calles y Domeño, donde era frecuente en los pinares que se extendían por estos términos. Tras los incendios que arrasaron en junio de 1994 la región y que prácticamente acabaron con toda la superficie forestal de pinar, no ha vuelto a localizarse pese a repetidos intentos por nuestra parte. En cuanto a las poblaciones valencianas de P. mannii, son tres el número de generaciones a lo largo del año que parece presentar la especie, equivalente a lo que ocurre en las poblaciones alicantinas. Se han encontrado poblaciones asentadas en pinares de Pinus nigra en localidades de los municipios turolenses de Torrijas y Camarena de la Sierra, localidades que distan apenas un kilómetro de la frontera con la Comunidad Valenciana, lo que hace muy probable que tales poblaciones puedan hallarse extendidas hasta el interior de las provincias de Castellón y Valencia.

\section{Colotis evagore (Klug, 1829)}

MATERIAL ESTUDIADO: VALENCIA: Llíria, 30SYJ08; 10", 24-VIII-1995 (J.A. García-Alamá). CGA; 10", 25-VIII1995 (J.A. García-Alamá). CGA; $50^{7} 0^{7}, 1$ \& , 28-VIII-1995 (J.A. García-Alamá). CGA; 50" $0^{\prime \prime}$, 1-IX-1995 (J.A. García-Alamá). CGA; $30^{7} \sigma^{7}, 2$ 2-IX-1995 (J.A. García-Alamá). CGA; $50^{7} 0^{7}, 1$ \% , 3-IX-1995 (J.A. García-Alamá). CGA; 10", 9-IX-1995 (J.A. García-Alamá). CGA; $10^{7}, 3$ ᄋ , 13-X-1995 (J.A. GarcíaAlamá). CGA; 407 $0^{\pi}, 3$ ㅇ , 14-X-1995 (J.A. García-Alamá). CGA; 23-XI-1996, varias orugas sobre Capparis spinosa. (J.A. García-Alamá); 1 ㅇ , 5-IX-2001 (J.A. García-Alamá). CGA; 1 우, 7-X-2001 (J.A. García-Alamá). CGA; 60 $0^{7} \sigma^{7}, 6$ ㅇ \& IX-X-2001, (S. Montagud). CSM; 160 $0^{\pi}, 11$ 우 인 21-X-2001, (S. Montagud). CSM. Llíria, 30SYJ09; 1 \%, 22-IX-1995, (S. Montagud). CSM; $10^{7}, 1$ , 23-X-1995, (S. Montagud). CSM; 1 , 29-X-1995, (S. Montagud). CSM; 20 $0^{7}$, 30-IX-2001, (S. Montagud). CSM; $160^{\pi} 0^{x}, 10$ ㅇ $~$, 7-X-2001, (S. Montagud). CSM; $20^{7} \sigma^{7}, 2$ ㅇ ㅇ, 26-X-2001, (S. Montagud). CSM; 1 \% , 5XI-1995, (S. Montagud). CSM; 50 $0^{x}, 1 \%$, 17-XI-2001, (S. Montagud). CSM. Massarrojos, 30SYJ28; 10 , 1-XI- 1995, (J. Domingo). ICBiBE. Náquera, 30SYJ29; $40^{\pi} 0^{\pi}, 3$ ㅇ $~, 21-\mathrm{X}-$ 2001, (S. Montagud). CSM. Olocau, 30SYJ19; 10", 26-XI-1995, (S. Montagud). CSM.

Durante la última semana de agosto de 1995 localizamos una población de esta especie bien establecida en las inmediaciones del casco urbano de Llíria, en las proximidades de matas de alcaparra o alcaparrera sembradas (Capparis spinosa) cuyo cultivo es muy habitual en esta zona. La especie se encontraba muy extendida por varios términos municipales de las comarcas de València, L'Horta y el Camp del Turia, pero siempre relegada a las inmediaciones de alcaparras que en esta región son cultivadas tradicionalmente en bancales y lindes de tierras de labor y hasta el momento, nunca crecen silvestres. La máxima abundancia de adultos fue observada durante la última semana de septiembre y primera quincena de octubre. Estas poblaciones que llegaron a cerrar ciclos completos en tan sólo 20-25 días, sobrevivieron hasta bien entrado el invierno y durante los últimos días de diciembre era posible hallar aún larvas de todas las edades en las hojas de sus plantas nutricias. Con las primeras heladas desaparecieron completamente y a la primavera siguiente no se halló ningún ejemplar adulto en los mismos lugares donde unos meses atrás aparecían en abundancia. En verano y otoño de ese mismo año, 1996, pudieron capturarse unos pocos ejemplares en los mismos lugares, pero muy escasos; no se halló sin embargo ningún estado preimaginal. Esta 


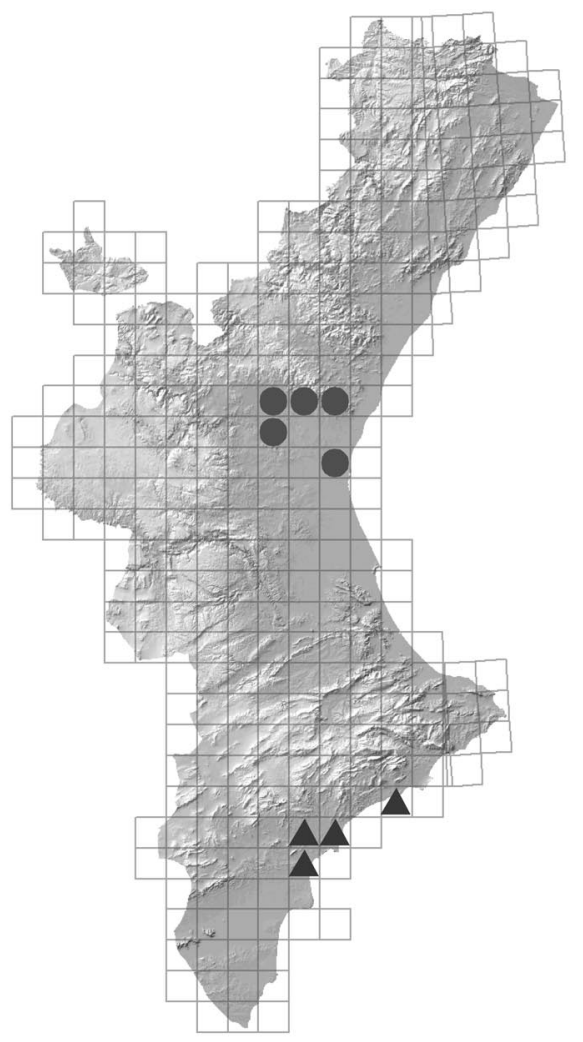

Fig. 4.- Colotis evagore.

misma situación se repitió durante el año 1997 y a partir de entonces, la especie pareció desaparecer completamente. Desde finales del verano de 2001, y hasta la llegada del invierno, se volvió a repetir el mismo escenario de 1995, apareciendo muy abundante en los mismos lugares donde antaño la habíamos recolectado. De nuevo se observaron los estados inmaduros y las poblaciones completaron varias generaciones hasta finales de diciembre, volviendo a desaparecer en cuanto las temperaturas descendieron. Desde entonces, sólo se ha avistado algún ejemplar errante en agosto de 2004.

Estas poblaciones localizadas en las inmediaciones de la ciudad de Valencia, distan mucho de las más cercanas conocidas, en la provincia de Alicante. Claro está que se trata de una especie migrante, que en años favorables puede alcanzar zonas muy al norte de su distribución constante y establecer poblaciones locales durante un tiempo más o menos prolongado. Pero para darse esta circunstancia es necesario la existencia de sus plantas nutricias. Muy probablemente, allá donde aparezcan matas de alcaparrera a lo largo del litoral mediterráneo español, existe una probabilidad alta de que se instalen poblaciones temporales de esta especie y esto parece ser más frecuente durante los meses de otoño. Así ha ocurrido recientemente en Lleida, una de las localidades más septentrionales en donde ha sido registrada (Stefanescu et al., 2005).

Son muchas las referencias sobre los hallazgos de Colotis evagore desde que se encontró por primera vez en Europa. La primera cita se dio a conocer a través de una pequeña nota publicada en la revista Graellsia (Agenjo, 1951), en la que se reseñaba la captura de un ejemplar y el avistamiento de varios más en las cercanías de Puerto Real, en Cádiz, el 17 de septiembre de 1950. Es interesante destacar que en la mayoría de los casos, los avistamientos o capturas se han efectuado en los meses de septiembre y octubre. Pongamos unos pocos ejemplos: en el pantano de Santomera, el 24 de septiembre de 1967, en el Puerto de Mazarrón, provincia de Murcia, junto a la playa, se recolectaron abundantes ejemplares entre el 1 y el 21 de septiembre y 1 de octubre de 1967, el autor de cuyas capturas, a pesar de veranear en dicha localidad, no la volvió a observar (Agenjo, 1969). Las observaciones del año 1968 de Sierra Nevada se verificaron el 8 de septiembre y en las cercanías de la playa de Almería durante septiembre del mismo año (Agenjo, 1969). En la Sierra de Gádor (Almería), en septiembre de 1968, en la Laguna de Zoñar (Aguilar de la Frontera) y río Guadajoz, en la provincia de Córdoba, durante octubre de 1983 (Fernández-Haeger, 1986), en Moraleda de Zafayona, Granada, el 30 de septiembre y a lo largo del mes de octubre de 1984 (Pascual-Linares, 1984), en los municipios de Alcudete, y Úbeda, en Jaén, durante octubre y noviembre de 1984 (Pascual-Linares, 1985) y recientemente, en Tortosa, provincia de Tarragona, a finales del mes de agosto de 2002 (Fric, 2005), comarca del Segrià, Lleida, en octubre de 1995 y septiembre de 2004 (Stefanescu et al., 2005) y por último en la la localidad de Mequinenza, Zaragoza, durante septiembre y octubre de 2005 (Pérez de-Gregorio et al., 2006). Todos estos datos apuntan a ejemplares divagantes de generaciones tardías que se aventuran en migraciones hacia el norte y de manera casual (o no) acceden a territorios donde crecen matas de $C$. spinosa. Aquí pueden establecerse y dar lugar a dos o tres generaciones más, en función de las temperaturas, cuyas poblaciones suelen ser más sedentarias que sus predecesores y frecuentemente alcanzan altas densidades de ejemplares. Con la llegada de los primeros fríos invernales desaparecen tanto los adultos como los estadios preimaginales. La puesta y desarrollo de las larvas es posible en todos aquellos lugares de nuestra geografía en donde subsista la planta nutricia y se den las temperaturas suficientemente altas para que esto suceda, esto es hasta noviembre en el peor de los casos. Agenjo apuntó que podría considerarse esta especie aclimatada o no en base a la existencia de larvas y al completo desarrollo de las mis- 
mas y que esta observación podría ser apodíctica. Sin embargo, como hemos visto, pese a la puesta y desarrollo de las larvas e incluso completando el ciclo biológico varias veces, las poblaciones desaparecen en los primeros fríos. Queda claro, por tanto, que la mayoría de las poblaciones ibéricas, especialmente las catalanas, aragonesas y del interior peninsular son temporales. Este argumento puede reforzarlo el hecho de que a pesar de las numerosas veces que hemos criado esta especie a partir de larvas o huevos obtenidos en la naturaleza, en ningún caso hemos logrado un sólo parasitoide. Sólo en ciertas zonas favorables de España que reúnan condiciones de clima templado durante los meses de invierno, sus poblaciones han podido establecerse y cerrar el ciclo biológico a lo largo de todo el año, pasando a considerarse ya como especie residente en la Península Ibérica. Esto parece suceder en la costa de Cádiz y Málaga (Arrebola, 1986). En estas localidades aparece en trescuatro generaciones repartidas a lo largo de todo el año y aparentemente no existe ningún estado de diapausa invernal. Un tema fundamental a tratar respecto a su supervivencia en los meses invernales lo constituye la biología de su planta nutricia. La alcaparra pierde completamente la hoja hacia diciembre y no la retoma hasta bien entrado marzo en gran parte de su distribución ibérica. Si las generaciones se suceden sin interrupción y no existe diapausa invernal en ningún estadio, la pérdida foliar se convierte en un problema para la supervivencia de las larvas y parece ser la principal causa de su desaparición en muchas de las localidades ibéricas, aún cuando los inviernos sean moderados y permitan la continuidad del ciclo. Pero en ciertos puntos litorales de Málaga y Cádiz donde se da una climatología adecuada en invierno y ciertas condiciones de aridez (la planta no tolera bien precipitaciones mayores de $450 \mathrm{~mm}$ anuales), muchos de los arbustos de alcaparra pierden la hoja y rebrotan en un rango de tiempo bastante dilatado e independiente, de forma que siempre es posible encontrar alguna mata con hojas que al perderlas, otras próximas han comenzado con el rebrote (Arrebola, 1986; Jordano et al., 1991). En el Norte de África se citan como plantas nutricias alternativas los géneros Cadaba y Maerua, ambas con especies perennes que permitirían cerrar el ciclo a lo largo de todo el año. Algunos autores han pretendido relacionar la expansión hacia áreas cada vez más septentrionales de Colotis evagore con el reciente cambio climático (Fric, 2005). Más bien este efecto estaría acusándose sobre el comportamiento de caída foliar y rebrote de las plantas de Capparis y como síntoma secundario, afectaría en el potencial colonizador de esta mariposa en áreas alejadas de su distribución constante. El núcleo de los individuos migrantes procede del norte de África, aumentado probablemente con algún contingente del sureste penínsular.

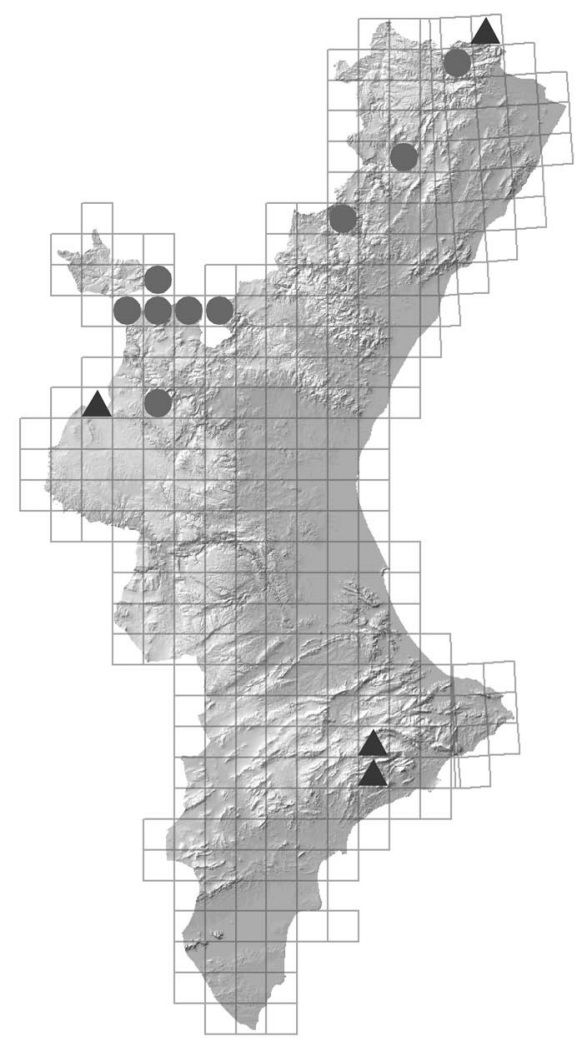

Fig. 5.- Aporia crataegi.

\section{Aporia crataegi (Linnaeus, 1758)}

MATERIAL ESTUDIADO: CASTELLÓN: Barranc dels Horts, Ares del Maestre, 30TYK47; 10', 24-V-2001 (S. Montagud et al.). CSM. El Coratxar, Pobla de Benifassar, 31TBF50; $20^{\pi} 0^{\prime}, 1 \%$, 14-VI-2002 (S. Montagud). CSM. Penyagolosa, Vistabella del Maestrazgo, 30TYK25; 1 \& , 23-V2002 (S. Montagud). CSM; 30 $0^{\pi}, 1$, , 17-VI-2002 (S. Montagud). CSM; $30^{7} \sigma^{\pi}$, 1 \& , 17-VI-2002 (S. Montagud). CSM; 10", 27-VI-2002 (S. Montagud). CSM; 10", 28-VI-2002 (S. Montagud). CSM. $20^{x} \sigma^{x}$, 4-VII-2002 (S. Montagud). CSM; 10", 20-VII-2002 (S. Montagud). CSM. Sima del Estepar, El Toro, 30SXK82; larvas sobre Prunus spinosa; 30-IV-2005 (S. Montagud). VALENCIA: Sierra de Javalambre, Alpuente, 30SXK62; $20^{\pi} 0^{\pi}$, 5-VII-2004 (J.A. García-Alamá). CGA; 23VI-1996 (J.A. García-Alamá). CGA. Aras de los Olmos, Aras de Alpuente, 30SXK52; 107, 21-V-2006 (S. Montagud, A. Pérez-Onteniente \& M.A. Ibáñez-Orrico) FETS CEGN. Collado del Buey, Puebla de San Miguel, 30TXK63; 10" , 28-V2006 (S. Montagud \& M. Ibáñez-Orrico). CSM. La Canaleja, La Yesa, 30SXK72; 10", VI-2001 (S. Montagud et al.). CSM. $\mathrm{S}^{\mathrm{a}}$ del Negrete, Requena, 30SXJ68; larvas de último estadío sobre Crataegus monogyna; 27-IV-2003 (S. Montagud).

Se trata de una especie común y extendida en la Península Ibérica; sin embargo son verdaderamente 
escasos los datos relativos a su presencia en la Comunidad Valenciana. Había sido citada de la Aldea de la Torre, término municipal de Utiel, Valencia (Blat Beltrán, 1982) y Fredes, provincia de Castellón (Calle, 1983). De Alicante la refieren Robert et al. (1983) pero basándose en citas de un autor anterior que al parecer la halló en la Sierra de Aitana y la región de Sella (Maixner, 1975). Pese a repetidos intentos, no ha vuelto a observarse en aquellas localidades, por lo que parece aconsejable mantenerla como extraña a la fauna alicantina hasta que no se den nuevos registros.

Es una especie muy ligada al majuelo (Crataegus monogyna), sobre el que hemos encontrado sus larvas, gregarias, en las provincias de Valencia y Castellón. También se hallan sobre otras rosáceas silvestres como Prunus spinosa (fueron observadas sobre esta planta en la provincia de Castellón) y otras cultivadas. En la Comunidad Valenciana se encuentra en zonas elevadas y/o de interior en donde se dan las condiciones óptimas para el crecimiento del majuelo, por el que muestra especial predilección. Es muy probable se amplíe su distribución por muchos de los sistemas montañosos de la provincia de Castellón, de los que aportamos sólo tres citas. Cabe referir que las poblaciones en el macizo del Penyagolosa son extraordinariamente abundantes y en varias ocasiones hemos sido alertados por la vigilancia forestal inquiriendo si podría resultar una plaga. Los datos ofrecidos para la provincia de Valencia son más novedosos. Tradicionalmente, la Sierra de las Cabrillas, entre los municipios de Utiel y Sieteaguas ha constituido una frontera natural en esta provincia, delimitando por un lado la fracción más mediterránea y litoral que se extiende hasta el mar y por el otro la zona más mesetaria y montana, hacia el interior. Los registros que aportamos se corresponden con esta última zona, siendo poco probable que la especie sobrepase este límite.

\section{Familia Nymphalidae}

\section{Erebia epistygne (Hübner, 1819)}

MATERIAL ESTUDIADO: VALENCIA: Collado del Buey, Puebla de San Miguel, 30TXK63; 10" 28-V-2006 (S. Montagud \& M. Ibáñez-Orrico) FETS CEGN. Sierra de Javalambre, Alpuente, UTM; $80^{7} 0^{7}, 4$ 우 우, 1-IV-1994 (J.A. García-Alamá). CGA; 10", 2 우, 8-IV-1995 (J.A. GarcíaAlamá). CGA; 10", 4-IV-1996 (J.A. García-Alamá). CGA. 1 \& , 5-IV-1997 (J.A. García-Alamá). CGA.

Aunque varias veces citada de la provincia de Castellón, todavía no había sido hallada en Valencia. De esta última provincia referimos tres localidades, todas ellas con un nexo en común, pertenecer a las estribaciones del Sistema Ibérico oriental y concretamente al macizo del Javalambre. No resulta por lo tanto extraña la

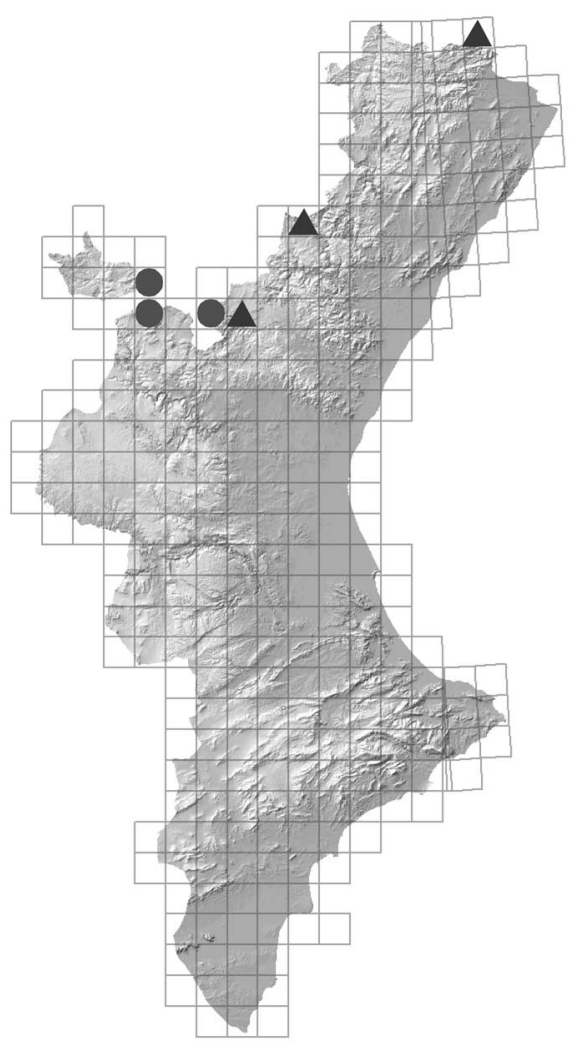

Fig. 6.-Erebia epistygne.

aparición de estas poblaciones, pues la especie ha sido registrada ya varias veces de la vertiente turolense de este macizo y del Sistema Ibérico en general. Sus poblaciones se asientan especialmente en terrenos pedregosos y despejados, a considerable altitud y pertenecientes a los pisos bioclimáticos supra y oromediterráneos. Así, es corriente en las laderas del Javalambre, por la pista que desde Torrijas alcanza esta cima. También es posible observarla a menores altitudes, ya en la zona de pinar (Pinus nigra y Pinus sylvestris) donde resulta más escasa. Como es bien sabido, a diferencia del resto de las especies del género, aparece siempre muy tempranamente y aquí lo hace en los meses de marzo o abril según la precocidad de la primavera, permaneciendo en vuelo hasta bien entrado el mes de mayo. Existe una población en la Sierra Lacera, provincia de Murcia (Lencina et al., 1998) que constituye la localidad más meridional en la distribución de la especie. Es interesante destacar que esta sierra se encuentra a tan sólo 10 kilómetros de la Sierra de la Solana, en la provincia de Alicante, que alberga cotas altitudinales similares. Prospecciones futuras podrían añadir esta especie al catálogo de lepidópteros alicantinos. 


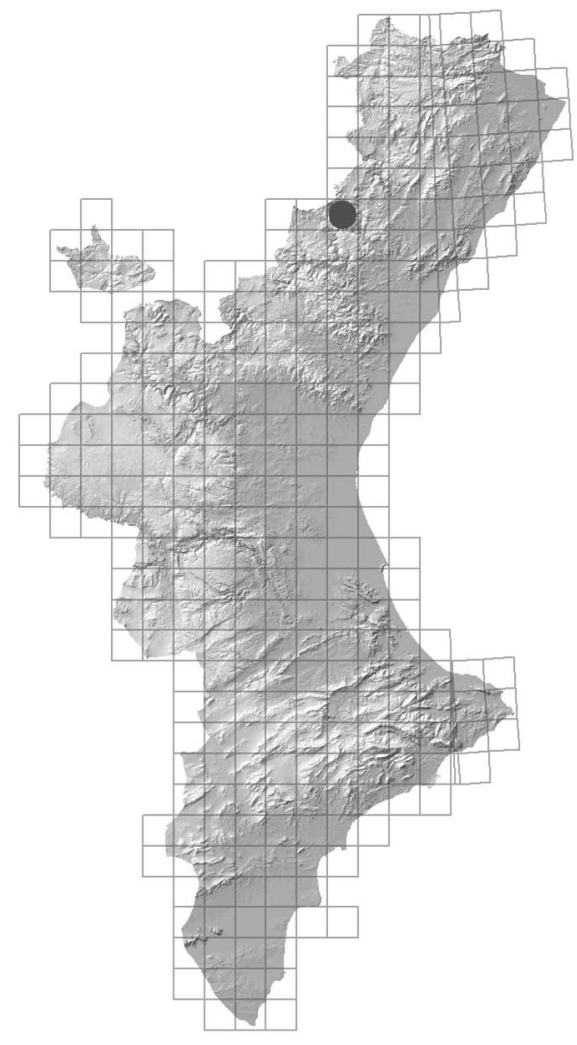

Fig. 7.-Erebia meolans.

7. Erebia meolans (de Prunner, 1798)

MATERIAL ESTUDIADO: CASTELlón: Penyagolosa, Vistabella del Maestrazgo, 30TYK25; 10", 9-VII-2002 (S Montagud). CSM.

No mencionada hasta ahora de la Comunidad Valenciana. Es muy probable que se encuentre en otras localidades castellonenses, especialmente aquellas relacionadas con el Sistema Ibérico en los sectores del Macizo de Javalambre y Gúdar, de donde se conoce su presencia en las vertientes de la provincia de Teruel.

\section{Melitaea cinxia (Linnaeus, 1758)}

MATERIAL ESTUDIADO: CASTELLÓN: Sima del Estepar, El Toro, 30SXK82; $10^{7}, 5$ ㅇ $q$, ex larva, sobre Plantago sp.; 30IV-2005 (S. Montagud et al.). CSM. VALENCIA: El Prao, Alcublas, 30SXK91; 1 ㅇ, ex larva, sobre Plantago sp.; III-2001 (S. Montagud et al). CSM. Fuente Jórgola, Domeño, 30SXJ79; $20^{7} 0^{7}, 1$ ㅇ, 3-V-1997 (J.A. García-Alamá). CGA; 60 $0^{x} 0^{x}$, 15-V1999 (J.A. García-Alamá). CGA; $20^{\pi} \sigma^{\pi}, 12-\mathrm{V}-2001$ (J.A. García-Alamá). CGA; $30^{7} 0^{\prime \prime}, 16-\mathrm{V}-2004$ (S. Montagud \& J. A. García-Alamá). CSM. La Pobleta, Andilla, 30SXK81; larva; 16IV-2006 (S. Montagud \& M.A. Ibáñez-Orrico). FETS_CEGN.

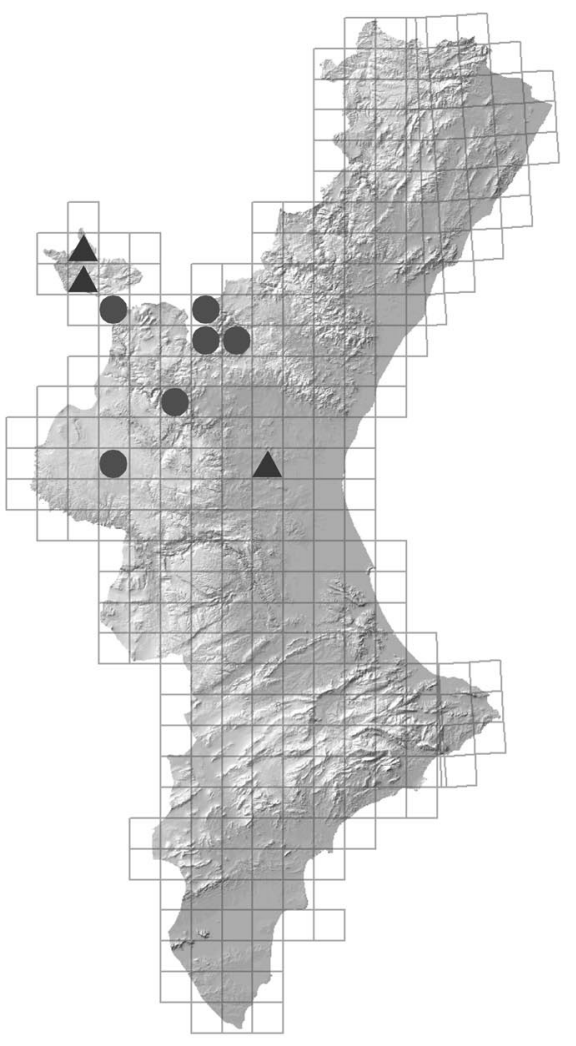

Fig. 8.- Melitaea cinxia.

El Pontón, Requena, 30SXJ57; 10", 30-IV-2006 (S. Montagud \& M.A. Ibáñez-Orrico). FETS_CEGN. Aras de los Olmos, Aras de Alpuente, 30SXK52; 10", 1 우, 21-V-2006 (S. Montagud, A. Pérez-Onteniente \& M.A. Ibáñez-Orrico). FETS_CEGN.

La especie sólo ha sido citada en la provincia de Valencia de las localidades de Torre Baja, Rincón de Ademuz (Blat Beltrán, 1982) y los Montes de Pozalet, municipio de Cheste (Huertas, 1974). Se halla sin embargo muy extendida en esta provincia, no siendo el caso en la de Castellón, de donde sólo hemos podido observarla en una localidad. No se conoce todavía de la provincia de Alicante. Sus poblaciones son muy locales, pero no escasas. Suelen preferir lugares húmedos, particularmente barrancos de orientación norte donde se desarrolla un manto herbáceo copioso y diverso. Las larvas deambulan por el suelo, mostrando un gregarismo que van perdiendo conforme alcanzan su desarrollo. Melitaea cinxia se alimenta de diversas especies del género Plantago, plantas que suelen estar muy extendidas y son frecuentes tanto en zonas forestales como transformadas, por lo que la restricción en la distribución de esta especie no parece recaer en su planta nutricia. De 
la localidad de Andilla se obtuvo, en abril de 2006, una larva sobre Plantago lanceolatum. De ella emergieron días después varios ejemplares de bracónidos pertenecientes al género Cotesia.

\section{Libythea celtis (Laicharting, 1782)}

MATERIAL ESTUDIADO: CASTELLÓN: Sierra de Espadán, 30SYK22; 1 \& , III-1993 (S. Montagud). CSM. La Mosquera, Almedíjar, 30SYK21; 1 \& , 10-III-2002 (S. Montagud) CSM. VALENCIA: Pantano de BenajeberBarchel, 30SXK60; 107, 12-VII-1988 (J. A. García-Alamá). CGA. Fuente Jórgola, Domeño, 30SXJ79; $20^{x} 0^{x}$, 27-VII-1988 (J. A. García-Alamá) CGA.

TERUEL: Fuente La Miel, Camarena de la Sierra, 30TXK63, $20^{x} 0^{x}, 22-$ VII-2001 (S. Montagud) CSM.

Es una especie hibernante que aparece muy tempranamente, hacia el mes de marzo, en los lugares con presencia de almez (Celtis australis), su planta nutricia. Estos individuos dan lugar a una generación estival, cuyos ejemplares serán los que en estado adulto pasarán el invierno refugiados en cavidades, cobertizos, oquedades, etc. En casos excepcionales, puede darse una segunda generación parcial en verano. Esta especie debe hallarse muy extendida en nuestro territorio, especialmente en aquellos lugares donde abunde el almez, muy frecuente en las proximidades de acequias y cursos de agua de nuestra geografía. Pero no siempre se encuentra asociada a su planta nutricia. Se conocen migraciones locales y estacionales de esta especie que asciende a cotas más altas donde pasar los meses más calurosos del año. Estas zonas se encuentran a menudo fuera de la influencia del almez. Hemos podido observar un fenómeno de este tipo en el municipio turolense de Camarena de la Sierra durante el verano de 2001, en cuyas proximidades y en torno a los 1550 metros de altitud, ya en zonas de pinares de Pinus nigra y Pinus sylvestris, fue posible observar en diversas jornadas numerosos individuos acudiendo a libar a las flores de Eryngium campestre. Observaciones muy parecidas han sido referidas de otras localidades de Europa, como es el caso del Monte Ventoux y el macizo subalpino de Cévennes, en Francia o en el macizo de Pindo en Grecia (Lafranchis, 2000, 2004). Así pues, las observaciones de esta especie en zonas nada apropiadas para el desarrollo del Celtis australis, muy frecuentes en la bibliografía lepidopterológica española, debe atribuirse a este tipo de movimientos estacionales. Una vez superado el verano, los individuos regresan de nuevo a cotas menos elevadas donde buscarán refugios para hacer frente al invierno. Sería interesante poder constatar si este tipo de migraciones se verifican todos lo años e implican siempre al mismo conjunto de poblaciones.

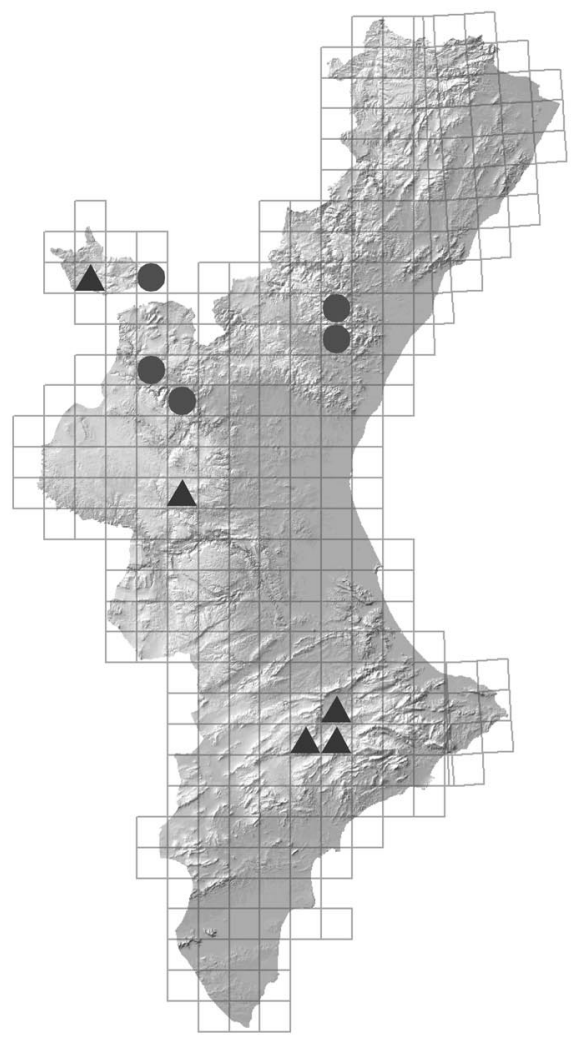

Fig. 9._Libythea celtis.

10. Danaus plexippus (Linnaeus, 1758)

MATERIAL ESTUDIADO: ALICANTE: Alrededores de Terra Mítica, Benidorm, 30SYH47; 2 우, 1-XII-2001 (S. Montagud) CSM; $50^{7} \sigma^{7}, 2$ 우 으, ex ova, sobre Asclepias curassavica; 1-XII-2001 (S. Montagud) CSM; $20^{7} \sigma^{\pi}, 1$ ㅇ, 3-I-2002 (S. Montagud) CSM; $30^{7} 0^{7}, 4$ ㅇ ㅇ , 27-XII-2001 (S. Montagud \& J.A. García-Alamá) CSM.

Existen registros desde el siglo XIX de la Península Ibérica, especialmente en la zona del Algarve y el estrecho de Gibraltar. También ha sido mencionada repetidamente de la costa atlántica, atribuyéndose muchas veces a ejemplares arrastrados desde sus vías migratorias en Norteamérica por vientos particularmente violentos. Durante la década de los 80 se instalaron varias poblaciones en las provincias de Murcia, Granada, Málaga y Almería (Masó et al., 1983; García-Barros et al., 2004), especialmente en la localidad malagueña de Torrox, de donde parece haber desaparecido durante los años 90 debido en parte a la urbanización de los terrenos en los que se había asentado. Desde entonces la especie no había sido registrada. En diciembre de 2000, uno de los autores encontró una importante población establecida dentro de 


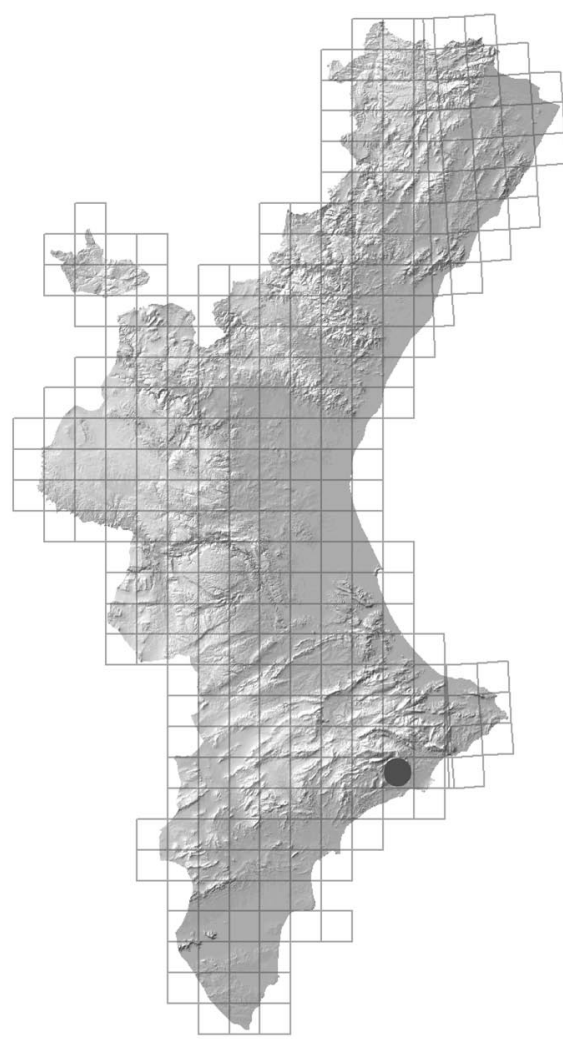

Fig. 10._Danaus plexippus.

los límites del parque temático de "Terra Mítica", en el municipio de Benidorm, Alicante. La especie era tan abundante que una de las primeras hipótesis que barajamos fue la suelta expresa de individuos por la dirección del parque. La población parecía establecida en el interior del recinto y pese a varios intentos no se localizaron más individuos fuera del perímetro salvo algunos pocos en la zona de los aparcamientos, donde acudían a libar a las flores de Lantana camara. Dentro del recinto fueron observadas algunas matas de Asclepias con puestas y primeros estadios larvarios, pero las plantas eran tan escasas y de tan corto porte, que no creímos posible se pudiera desarrollar otra generación. Sin embargo, en dos visitas que se realizaron a finales de diciembre y principios de enero se encontraron ejemplares en perfecto estado que indicaban una eclosión reciente. Consideramos que era probable que estuvieran desarrollándose en una planta alternativa y estuvimos buscando entre las que allí existían. Encontramos una crisálida muerta y varias señales de hojas devoradas por larvas en un arbusto de Thevetia peruviana, planta de la familia de las apocináceas que también rezuma un latex tóxico cuando se quiebra o corta. No obstante, el daño en estas plantas no era suficiente como para coincidir con la alta densidad de ejemplares observados. Posteriormente nos comunicó uno de los encargados de la jardinería del Parque, con quien nos pusimos en contacto para resolver la cuestión, la existencia previa a nuestras visitas de parterres con abundantes Asclepias; sin embargo su cultivo fue abandonado después de observar que eran completamente defoliadas por las larvas de Danaus, que al parecer ya existía allí desde el mes de agosto. Todos estos datos parecían indicar una estrecha relación entre la importación de Asclepias y la aparición de la mariposa monarca. Intentamos averiguar la procedencia de las plantas y pudimos conocer la implicación de dos viveristas de diferentes comunidades autónomas que habían ejecutado la importación, pero pese a repetidos intentos por nuestra parte, nunca logramos averiguar el origen de estas plantas. Creemos que la aparición accidental de esta población puede ser debida a una importación de matas de Asclepias sin los correspondientes controles fitosanitarios oportunos, que trasladan junto a ellas huevos o larvas de la mariposa y esta, en condiciones favorables, consigue aclimatarse. Otra hipótesis posible es el establecimiento de una población temporal más en el mediterráneo, circunstancia que se ha dado ya varias veces en varias provincias andaluzas. El origen de estas poblaciones temporales podría deberse a fenómenos de migración desde áreas cercanas, como las Islas Canarias (para cuyas poblaciones aún no se ha comprobado actividad migratoria) o con mayor seguridad, a importaciones debidas a la mano del hombre como parece ser que ha ocurrido no sólo en España, sino en Madeira (Showler, 2001). En cualquier caso, desde entonces no ha vuelto a ser observada en Alicante. No debe por tanto considerarse una cita nueva para la provincia sino una introducción involuntaria que no se ha arraigado.

\section{Familia Lycaenidae}

\section{Plebeius (Aricia) morronensis Ribbe, 1910}

MATERIAL ESTUDIADO: CASTELLÓN: Penyagolosa, Vistabella del Maestrazgo, 30TYK25; 40 $0^{x}$, 3-VIII-2002 (S. Montagud et al.) CSM.

Especie de zonas montañosas, en la Comunidad Valenciana se había citado de la Sierra de Aitana, provincia de Alicante en 1976. Hoy en día es una especie frecuente en esta localidad. No es el caso de las poblaciones de Penyagolosa, en Castellón; su descubrimiento es interesante. El Dr. Munguira encontró un huevo en un ejemplar de Erodium cheilanthifolium var. valentinum de un pliego del herbario del Jardín Botánico de Madrid, procedente de esta localidad, a una altitud de $1700 \mathrm{~m}$ y con fecha nada menos que de julio de 1910 (año de su descripción), que asignó correctamente a esta especie 


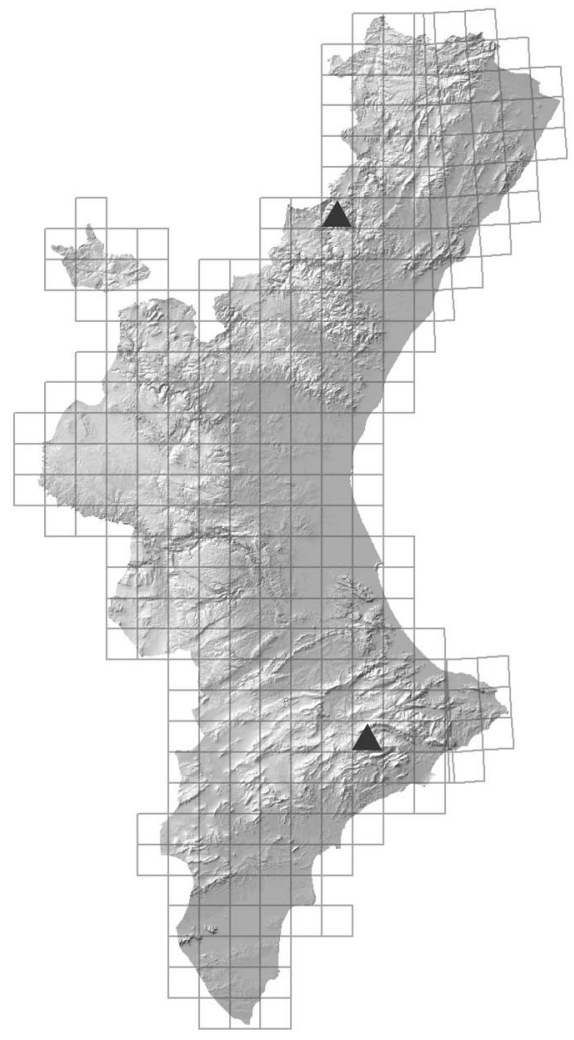

Fig. 11._- Plebeius (Aricia) morronensis.

(Munguira, 1989). Pero su presencia actual aún no estaba comprobada con ejemplares adultos. Durante el año 2002 realizamos un estudio poblacional de la población de Parnassius apollo (Linnaeus, 1758) que se encuentra enclavada en esta cumbre y el proyecto requirió de frecuentes campañas de muestreo durante los meses de junio, julio y agosto. Hacia principios del mes de agosto pudimos localizar en la vertiente noroeste de este macizo una escasa población de $A$. morronensis que volaban en torno a unas pocas matas de Erodium, con lo que quedó confirmada la presencia de esta especie (García-Barros et al., 2004). Esta población se encuentra muy restringida tanto en espacio como en número de ejemplares, en una cota entre los 1600 y $1815 \mathrm{~m}$ de altitud en la cumbre. No parece probable que se encuentre a cotas más bajas, pues la zona ha sido inspeccionada con regularidad por entomólogos. La planta sobre la que se desarrolla en este punto es Erodium celtibericum (antes E. cheilanthifolium ssp. celtibericum ó E. valentina), un endemismo del Sistema Ibérico localizado en las cumbres apenas sin vegetación de las Sierras de Castellón, Teruel, Tarragona y Cuenca. Parece plausible considerar que en las cotas altitudinales $\mathrm{y}$ entorno necesarios para esta mariposa no existe otro

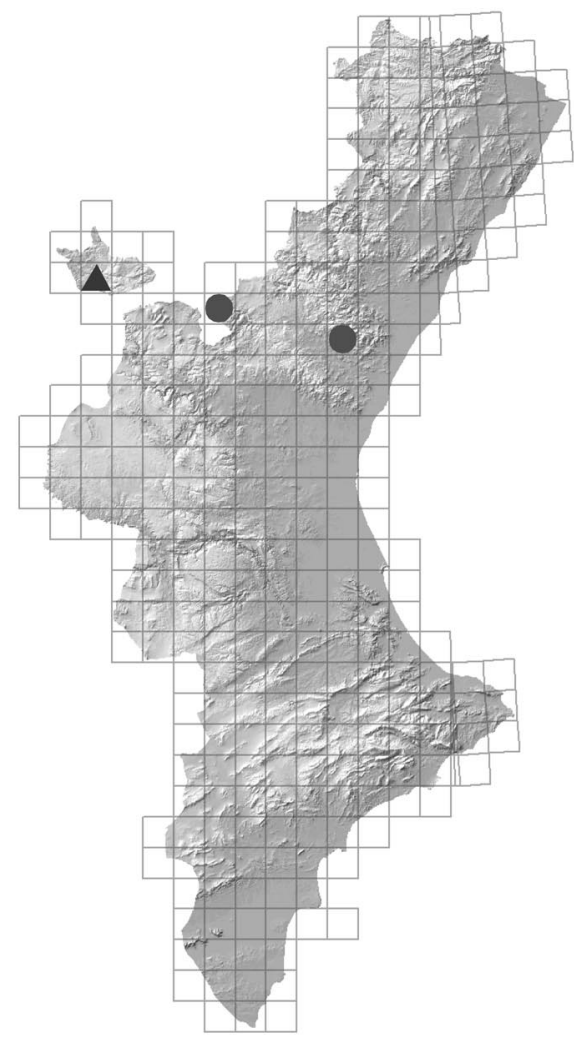

Fig. 12.- Glaucopsyche (Iolana) iolas.

Erodium y por lo tanto se produciría una asociación planta-insecto delimitada por una combinación de al menos dos factores: altitud y hábitat. Es por esto que, una práctica de reforestación en este tipo de hábitats podría poner en peligro a esta especie, de la que tenemos noticia de su existencia en este lugar, al menos desde 1910.

Se trata de una especie endémica de la Península Ibérica localizada en los principales sistemas montañosos. Las poblaciones de la Comunidad Valenciana constituyen los dos extremos más cercanos de su distribución entre el Sistema Ibérico y el Sistema Bético.

12. Glaucopsyche (Iolana) iolas (Ochsenheimer, 1816) MATERIAL ESTUDIADO: CASTELLÓN: Almedíjar, 30SYK21; $50^{\pi} 0^{\pi}, 2$ 우 ㅇ, 17-IV-2001 (S. Montagud). CSM. TERUEL: Mora de Rubielos, 30TXK96, 107, 1-V-1997 (S. Montagud). CSM. Abejuela, 30SXK82, 10", 22-VI-2002 (S. Montagud). CSM.

Tan sólo existe una cita valenciana de esta especie en el Rincón de Ademuz (Hecq, 1991). Hemos podido localizar una población en la Sierra de Espadán, provincia de Castellón, en torno a un pequeño bosquete de Colutea 


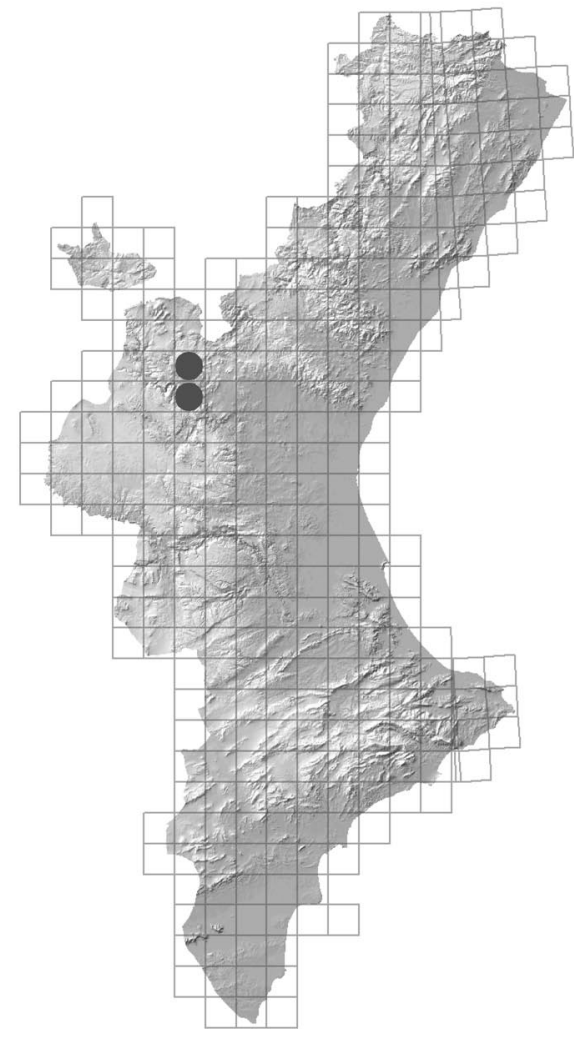

Fig. 13.- Polyommatus (Meleageria) daphnis.

arborescens. La sierra de Espadán constituye una de las estribaciones orientales del Sistema Ibérico, en cuyos relieves se encuentran afincadas poblaciones de $G$. iolas conocidas desde antaño, principalmente en la Sierra de Albarracín (García-Barros et al., 2004). Entre el Rincón de Ademuz y las poblaciones de Castellón existen poblaciones intermedias en las localidades de Abejuela y Mora de Rubielos, en la provincia de Teruel. La especie debe encontrarse bien extendida por todo el Sistema Ibérico meridional, pero siempre limitada a la presencia de su planta nutricia que crece de forma local y aislada. Aunque algunos autores refieren una mirmecofilia muy acusada con el formícido Tapinoma erraticum (Gómez Bustillo et al., 1974, que lo citan como género Myrmica; Tolman et al., 2002) lo cierto es que no se trata de una simbiosis obligada, por lo que la ausencia del himenóptero no condiciona la presencia de la mariposa.

\section{Polyommatus (Meleageria) daphnis (Denis \&} Schiffermüller, 1775)

MATERIAL ESTUDIADO: VALENCIA: Fuente Jórgola, Domeño, 30SXJ79; 10", 5-VIII-1992 (J.A. García-Alamá).
CGA. Mas de Herrero-Calles, $20^{x} 0^{x}, 1 \%$, 20-VII-2006 (J.A. García-Alamá). CGA; 10", 22-VII-2006 (J.A. García-Alamá \& S. Montagud). CGA.

Especie muy localizada; hasta el momento no se conocía de la Comunidad Valenciana. Se ha encontrado una población en los terminos municipales de Calles y Domeño, provincia de Valencia, a una altitud de $500 \mathrm{~m}$ y $811 \mathrm{~m}$. De la localidad de Domeño, también provincia de Valencia, sólo se conoce un ejemplar, pese a repetidos intentos de búsqueda en la zona. Del término municipal de Calles se conocen tres ejemplares machos y una hembra recolectados en 2006. Estas localidades son las más meridionales conocidas para esta especie en la Península Ibérica. Debe encontrarse más extendida por la zona, aunque siempre en puntos muy localizados. Las poblaciones más cercanas registradas hasta la fecha en los alrededores de Albarracín (Teruel) y Serranía de Cuenca distan muchos kilómetros. Probablemente se encuentren poblaciones intermedias a lo largo del Sistema Ibérico meridional, pero resulta extraño que no haya aparecido esta especie en las sierras de Javalambre o Gúdar, a pesar de trabajos de prospección importantes realizados en los último años (Tarrier, 1993; Sánchez-Rodríguez et al., 1995).

Ha sido citada también de los alrededores de Monte Caro, en la provincia de Tarragona (Bellavista et al., 1989) con lo que puede encontrarse distribuida por todo el sector del Maestrazgo y mantener enclaves dentro de la provincia de Castellón. Las larvas se alimentan de un amplio espectro de leguminosas, entre las cuales parecen mostrar predilección por varias especies de Astragalus, género de amplia repartición en las tres provincias.

\section{Scolitantides orion (Pallas, 1771)}

MATERIAL ESTUDIADO: CASTELLÓN: Barranc dels Horts, Ares del Maestre, 30TYK47; 10", 24-V-2001 (S. Montagud). CSM. El Coratxar, Pobla de Benifassar, 31TBF50; $10^{x}, 14-\mathrm{VI}-2002$ (S. Montagud). CSM.

TERUEL: Abejuela，30SXK82; 10 , 22-VI-2002 (S. Montagud). CSM.

Especie muy localizada, siempre hallada de forma esporádica y dispersa. Conocida de las provincias de Alicante y Valencia, hasta ahora no había sido citada de Castellón. Las citas valencianas y alicantinas son, sin embargo, muy antiguas. Del Coll de Rates, municipio alicantino de Tárbena, fue citada en 1970 y hasta el momento no ha vuelto a ser observada; la otra localidad alicantina, el Montgó, de donde se mencionó en 1974 en base a ejemplares de una colección confeccionada por alumnos (lo que predispone a considerar la cita con cautela), ha sufrido repetidos e intensos incendios en las últi- 


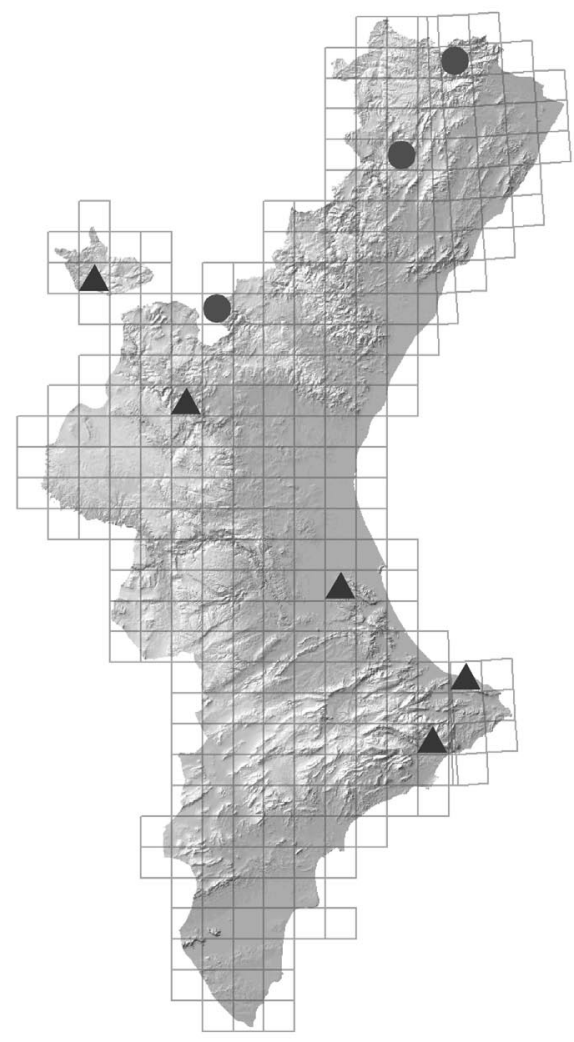

Fig. 14.- Scolitantides orion.

mas décadas, por lo que su presencia actual en la provincia, aún queda por comprobar. De la provincia de Valencia sólo ha sido referida del Rincón de Ademuz (SánchezRodríguez et al., 1995), en donde debe hallarse bien extendida, y el Embalse de Loriguilla (Bort, 1982). Esta última localidad también ha sufrido incendios recientes y a pesar de haber sido muestreada en varios puntos cercanos, la especie no ha vuelto a localizarse. Por último, existe un ejemplar en el Museo Nacional de Ciencias Naturales, procedente de Corbera (Valencia) y con fecha de 24-IV-1972, sin colector (García-Barros, com. pers.). Aportamos dos localidades castellonenses, pero sin duda debe encontrarse más extendida por los sistemas montañosos del interior de Valencia y Castellón. Son sus plantas nutricias diferentes especies del género Sedum, entre las que muestra predilección por Sedum album y Sedum dasyphyllum, ambas muy extendidas y frecuentes.

15. Neozephyrus quercus (Linnaeus, 1758)

MATERIAL ESTUDIADO: CASTELLÓN: Puerto de la Bellida-Sacañet, 30SXK91; 40" $\sigma^{\text {* }}$, 1 \% , 6-10-VII-2003 (J.A. García-Alamá). CSM; $30^{\pi} \sigma^{\pi}, 5$ $~ \%, ~ 4-V I I-2003$ (J.A. García-

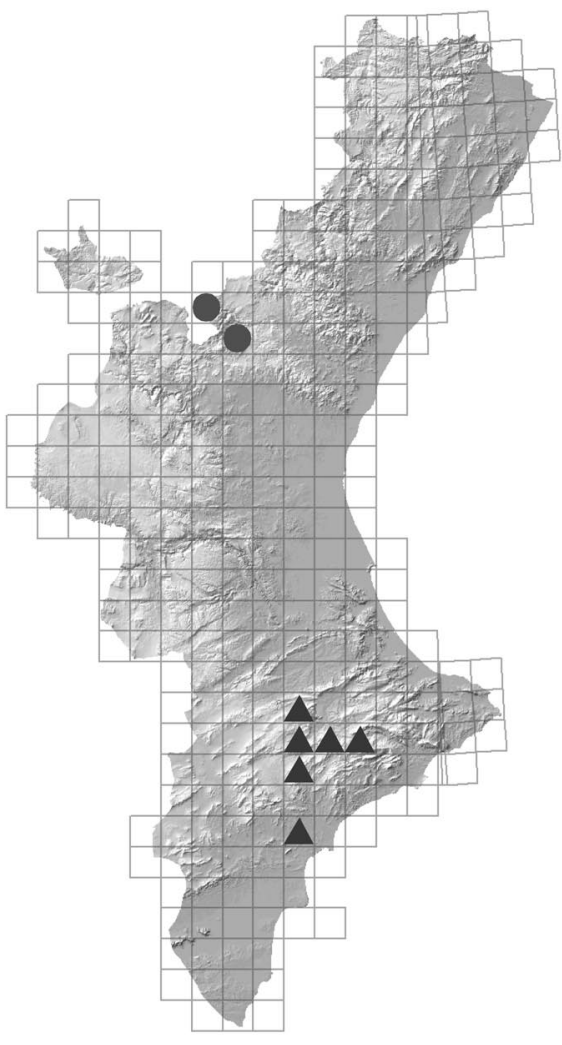

Fig. 15.- Neozephyrus quercus.

Alamá). CGA; $20^{7} 0^{7}, 2$ ㅇ \& , 6-VII-2003 (J.A. García-Alamá). CGA; $10^{\pi}, 10^{\pi}, 10-\mathrm{VII}-2003$ (J.A. García-Alamá). CGA; 2 ᄋ , 13-VII-2004 (J.A. García-Alamá). CGA; 2 ㅇ , 15-VII2004 (J.A. García-Alamá). CGA.

TERUEL: Alcotas, Manzanera, 30SXK82; 40 $0^{x} 0^{x} ; 26-\mathrm{VII}-$ 1994 (S. Montagud). CSM.

Muy extendida por la Península, faltando datos sobre su presencia en el levante, de donde sólo se conocía de las provincias de Murcia, Alicante y Tarragona. Debe encontrarse más distribuida en puntos del interior de la provincia de Valencia y Castellón, siempre ligada a bosques de encina y otros Quercus (exceptuando Quercus coccifera). En la provincia de Valencia, en el término municipal de Alcublas y limítrofe con el término municipal de Sacañet (Castellón) de donde son algunas capturas antes citadas, fueron observados 2 ejemplares volando alrededor de Quercus ilex.

16. Nordmannia acaciae (Fabricius, 1787)

MATERIAL ESTUDIADO: CASTELLÓN: Sant Joan de Penyagolosa, Vistabella del Maestrazgo, 30TYK25; $10^{7}, 28-$ 


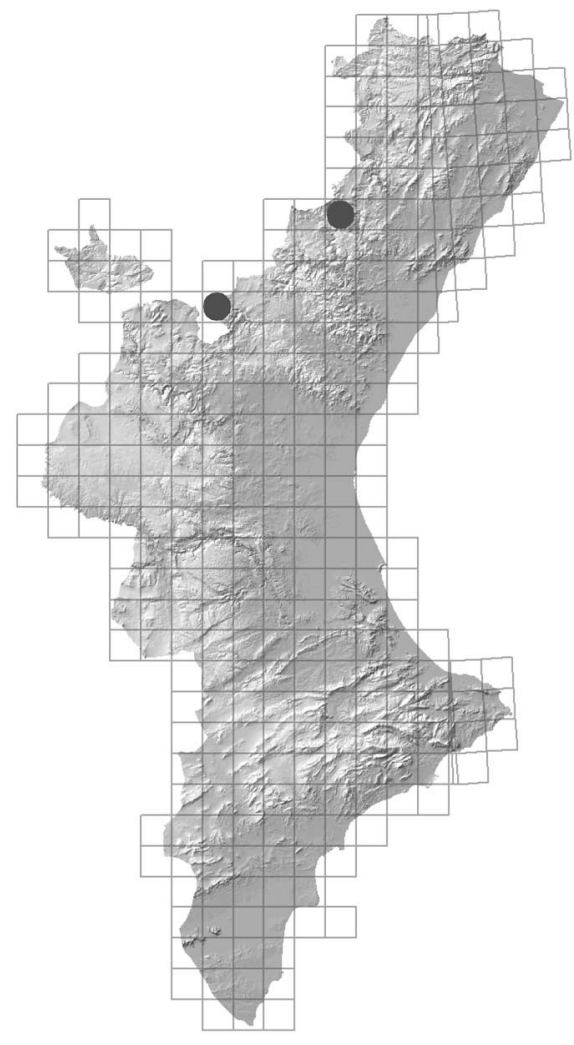

Fig. 16.-Nordmannia acaciae.

VI-2001 (S. Montagud). CSM; 1 , 17-VI-2002, (S. Montagud). CSM.

TERUEL: Abejuela，30SXK82，20 $0^{\pi}$, 22-VI-2002 (S Montagud). CSM.

Se encuentra muy repartida en el norte de la Península y es conocida también de algunos puntos aislados de la Sierra de Guadarrama y Sistema Ibérico meridional. Debe hallarse más extendida de lo que parece, presumiblemente confundida con $N$. esculi y $N$. ilicis. Por el Sistema Ibérico meridional penetra en la provincia de Castellón, en donde encontramos una población localizada en las cercanías de la cima del Penyagolosa. Su planta nutricia es el Prunus spinosa, abundante en esta localidad. Existe una cita aislada en la Sierra de Caro, Tarragona, lo que hace probable pueda encontrarse extendida por el Maestrazgo y alcance también por esta región la provincia de Castellón. En el término municipal de Torrijas-Teruel, escasamente a un kilómetro de la provincia de Valencia, termino municipal de Alpuente, se encuentra una importante población de esta especie, lo que no descarta que aparezca en la zona.

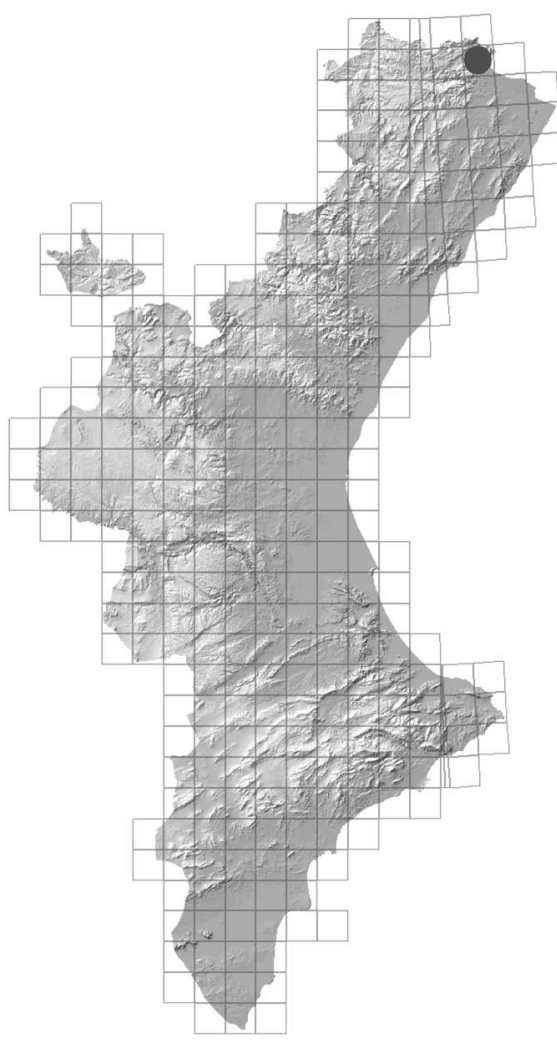

Fig. 17.-Laesopis roboris.

17. Laeosopis roboris (Esper, 1789)

MATERIAL ESTUDIADO: CASTELLÓN: Camí a la Fageda, Pobla de Benifassar, 31TBF60; $20^{\pi} \sigma^{\pi}$, 2-VII-2005 (S. Montagud, A. Pérez-Onteniente \& M.A. Ibáñez-Orrico). CSM.

No se tenían datos sobre su presencia en la Comunidad Valenciana, aunque Robert et al. (1983) presuponían su posible existencia en la provincia de Alicante, ligada a los bosquetes de fresnos de flor (Fraxinus ornus). Hemos encontrado una población al norte de la provincia de Castellón, casi en el límite con Tarragona, en las cercanías de varios ejemplares de Fraxinus angustifolia y Ligustrum vulgare. Debe encontrarse más repartida por la zona del Maestrazgo y Puertos de Beceite, como parece corroborarlo la cita de Tortosa, única referencia que se tiene de esta especie en la provincia de Tarragona. Al igual que Robert, confiamos hallarla en localidades de las provincias de Alicante y Valencia, donde existen importantes concentraciones de Fraxinus ornus, pero hasta el momento, nuestra búsqueda ha resultado infructuosa. Convendría confirmar si existen poblaciones ligadas a esta especie de fresno de distribución circunmediterránea, pues hasta ahora no tenemos referencias bibliográficas precisas que lo ratifiquen. 


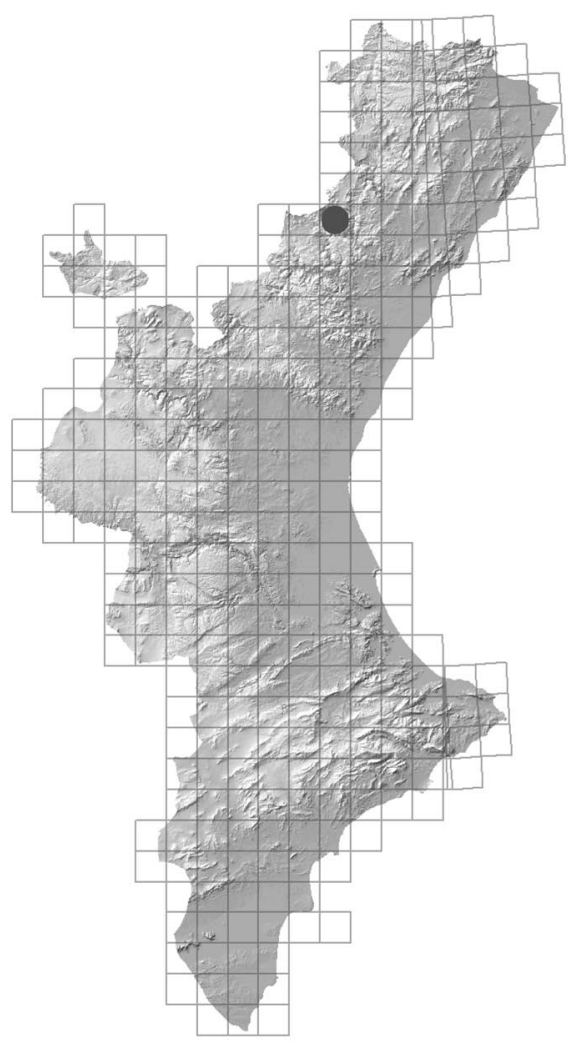

Fig. 17.- Plebeius hespericus.

18. Plebeius hespericus (Rambur, 1839)

MATERIAL ESTUDIADO: CASTELLÓN: Penyagolosa, Vistabella del Maestrazgo, 30TYK25; $20^{7} 0^{7}$, 17-VI-2002 (S. Montagud). CSM; 1 ㅇ, 20-VI-2002 (S. Montagud). CSM.

El complejo de taxones del grupo pylaon que se extienden en forma de pequeñas poblaciones relictas desde el sur de la Península Ibérica (Sierra Nevada y Sierra de Alfacar) hasta el centro del continente asiático, ha sido recientemente reordenado en cuatro especies de distribución europea. En la Península Ibérica se hallaría Plebeius hespericus con el límite septentrional de su distribución en el Sistema Ibérico, quedando bien separada geográficamente de su congénere Plebeius trappi Verity, 1927, cuyas poblaciones más cercanas se localizan en los Alpes. De la Comunidad Valenciana se conoce tan sólo una cita en los alrededores de Aitana (Tormo, 1983). Debido a lo aislado de esta reseña y a su singularidad, nos pusimos en contacto con el autor (que no volvió a recoger esta cita en catálogos posteriores) para indagar sobre su procedencia; parece ser que los ejemplares, de determinación dudosa, no han sido consultados por especialistas y procedían de una colección realizada por estudiantes del antiguo CEU de Alicante. Por todo ello, debemos tomar esta cita como errónea hasta no demostrarse lo contrario y por lo tanto mantener a $P$. hespericus como extraña a la fauna alicantina.

Se ha constatado su presencia en la Sierra de Gúdar, provincia de Teruel, que sin duda debe corresponderse con las mismas poblaciones del macizo del Penyagolosa, en el interior de la provincia de Castellón. Confirmada su ausencia en Alicante, la de Penyagolosa se trataría de la población más oriental de la Península. También mantiene poblaciones en la localidad turolense de Camarena de la Sierra, en plena Sierra de Javalambre, que penetra ampliamente en la provincia de Valencia por Ademuz y comarca de los Serranos. De esta localidad fue referida por Zapater y Korb (1883) y recientemente, con mayor precisión, en el valle del río Camarena (Tarrier, 1993) y cercanías del Pico de Javalambre (Sánchez-Rodríguez et al., 1995). Es por lo tanto muy probable su presencia en localidades propicias del interior de la provincia de Valencia. Sus zonas de vuelo, tanto en Camarena como en Penyagolosa, se corresponden con planicies abiertas de termoclima oromediterráneo o supramediterráneo extremo, donde su planta nutricia debe constituir mayoritariamente el Astragalus sempervirens, única especie del género que crece abundante en estos hábitats.

\section{AGRADECIMIENTOS}

Muy especialmente a Enrique García Barros por la aportación de información relativa a la distribución de especies en la Comunidad Valenciana y sus respectivas referencias. A Miguel L. Munguira, por sus indicaciones y separatas sobre Aricia morronensis y su descubrimiento en Castellón. A Elena Rodríguez, del Servicio de Conservación de la Biodiversidad de la Consellería de Territori i Habitatge, por la confección de los mapas y ayuda prestada en la obtención de coordenadas UTM. Juan José Herrero-Borgoñón nos ha asesorado en todo lo concerniente a la botánica (lo que viene ya siendo costumbre) con su habitual paciencia y experiencia. Este trabajo forma parte del proyecto "Realización de una investigación aplicada a la conservación de ropalóceros en las provincias de Alicante y Valencia" propuesto y financiado por la Dirección General de Gestión del Medio Natural, Conselleria de Territori i Habitatge, Generalitat Valenciana.

\section{Referencias}

Agenjo, R., 1951. Reseña de Capturas. Graellsia, 9: 3-7. AgENJo, R., 1959. Unas pocas mariposas valencianas. Graellsia, 17: 19-28.

Agenjo, R., 1969. Contribución al conocimiento de la fáunula lepidopterológica ibérica. Sección de capturas VI. Graellsia, 24: 49-60. 
Agenjo, R., 1970. Sobre la presencia en España de la Colotis evagore nouna Lucas, 1849 (Lep., Pieridae). Graellsia, 25: 141-148.

Agenjo, R., 1978. Contribución al conocimiento de la fáunula lepidopterológica ibérica. Sección de capturas X. Graellsia, 32: 3-18.

BAIXERAS, J., 1983. Recerques. 3. Espècies capturades a la Dehesa de "El Saler". Butlletí de la Societat Catalana de Lepidopterología, 40: 14-15.

Bellavista, J. \& Cervelló, A., 1989. Troballes interessants als Ports de Tortosa. Butlletí de la Societat Catalana de Lepidopterología, 62: 15-16.

Blat Beltrán, F., 1982. Avance de un catálogo de lepidópteros de Valencia, con indicación de las localidades de su captura, cazados por nosotros hasta el año 1973. SHILAP Revista de lepidopterología, 10(37): 55-58.

Bolland, F., 1984. Les papillons de la province de Castellón. SHILAP Revista de lepidopterología, 12(46): 114.

BORT, V., 1982. Relación de mariposas cazadas en la provincia de Valencia. SHILAP Revista de lepidopterología, 10(39): 231-232.

BoscÁ, A., 1916. Fauna Valenciana. En: Geografia General del Reino de Valencia, 1: 423-549.

Calle, J. A., 1983. Los lepidópteros de Castellón de la Plana. Confederación Española de Cajas de Ahorro. Madrid. 190 pp.

DocaVo, I. (ed.), 1987. La entomofauna del monte de Porta-Coeli. Edicions Alfons el Magnànim. Institució Valenciana d'Estudis i Investigació. Valencia. 188 pp.

Fernández-Haeger, J., 1986. Capturas de Colotis evagore (Klug, 1829) en el sur de España. Graellsia, 42: 233-235.

Font Bustos, J. M., 1978. Capturas más interesantes efectuadas en la provincia de Castellón. SHILAP Revista de lepidopterología, 6(24): 324.

Font Bustos, J. M., 1984. Diürnes del País Valencià i sud del Principat. Butlleti de la Societat Catalana de Lepidopterología, 42:11.

FrIC, Z., 2005. Colotis evagore (Klug, 1829) advancing northwards in Spain (Lepidoptera: Pieridae). SHILAP Revista de lepidopterología, 33(130): 169-171.

García-Barros, E. \& Munguira, M. L., 1999. Faunística de mariposas diurnas en España peninsular. Áreas poco estudiadas: una evaluación en el umbral del siglo XXI (Lepidoptera: Papilionoidea \& Hesperiidae). SHILAP Revista de lepidopterología, 27 (106): 189-202.

García-Barros, E., Munguira, M. L., Martín Cano, J., Romo Benito, H., García Pereira, P. \& Maravalhas, E. S., 2004. Atlas de las mariposas diurnas de la Península Ibérica e islas Baleares (Lepidoptera: Papilionidea \& Hesperioidea). Monografías S.E.A., 11. Zaragoza. 228 pp.
Gómez Bustillo, M. R. \& Fernández-Rubio, F., 1974. Mariposas de la Península Ibérica. Ropalóceros II. ICONA. Madrid. 258 pp.

HecQ, J., 1991. Notes de terrain: toujours l'Espagne entomologique; la province de Teruel et le Rincón de Ademuz. Lambillionea, 91: 97-105.

Huertas, M., 1974. Datos preliminares sobre los lepidópteros de Murcia y Valencia. SHILAP Revista de lepidopterología, 2(7): 231-234.

Jordano, D., Retamosa, E. \& Fernández-Haeger, C. J., 1991.Factors facilitating the continued presence of Colotis evagore (Klug, 1829) in Southern Spain. Journal of Biogeography, 18(6): 637-646.

LAFRANCHIS, T., 2000. Les papillons de jour de France, Belgique et Luxembourg et leurs chenilles. Collection Parthénope, editions Biotope. Mèze. $448 \mathrm{pp}$.

LAFRANCHIS, T., 2004. Quand les papillons changent d'habitat (2 ${ }^{\mathrm{e}}$ partie). Insectes, 132: 23-25.

Masó, A. \& Pérez De-Gregorio, J. J., 1983. Migració de Danaus chrysippus a la costa catalana, espècie nova per a Catalunya. Treballs de la Societat Catalana de Lepidopterología, 6: 55-64.

Munguira, M. L., 1989. Biología y biogeografia de los Licénidos Ibéricos en peligro de extinción (Lepidoptera, Lycaenidae). Tesis Doctoral. Servicio de Publicaciones, Universidad Autónoma de Madrid. Madrid. 462 pp.

MuÑoz, B., 1983. Algunas citas de lepidópteros de la provincia de Alicante y localidades cercanas. SHILAP Revista de lepidopterología, 11(43): 229-230.

PARDO, L., 1920. Las colecciones de animales inferiores, Moluscos y Artrópodos del Instituto General y Técnico de Valencia. Anales del Instituto General y Técnico de Valencia, 7: 95-104.

Pascual-Linares, J., 1984. Una nueva subespecie de Colotis evagore en la vega de Granada. SHILAP Revista de lepidopterología, 12(48): 339-340.

PASCuAl-Linares, J., 1985. Presencia de Colotis evagore en la provincia de Jaen. SHILAP Revista de lepidopterología, 13(1): 57.

Pérez De-Gregorio, J. J., Jeremías, X., RomañÁ, I. \& Rondos, M., 2006. Un nuevo ropalócero para Aragón: Colotis evagore nouna Lucas, 1849 (Lepidoptera, Pieridae). Boletín de la Sociedad Entomológica Aragonesa, 38: 339-340.

Robert, J. H., Escarré, A., García, T. \& Martínez, P., 1983. Lepidópteros ropalóceros. Cuadernos de la fauna alicantina, Instituto de Estudios Alicantinos. Alicante. 435 pp.

SÁnchez-Rodríguez, J. F. \& BAz, A., 1995. The effects of elevation on the butterfly communities of a Mediterranen Mountain, Sierra de Javalambre, Central Spain. Journal of the Lepidopterists' Society, 49(3): 192-207. 
SHOWLER, A., 2001. The possible introduction to Madeira of the monarch butterfly, Danaus plexippus (L.) (Lepidoptera). British Journal of Entomology and Natural History, 14: 43-44.

Stefanescu, C., Roca, M. C. \& Vidallet, D., 2005. Colotis evagore (Klug, 1829), espècie nova per a Catalunya (Lepidoptera: Pieridae). Butlletí de la Societat Catalana de Lepidopterología, 94: 117-120.

TARrier, M., 1993. Catalogue des Lépidopteres de la Sierra de Javalambre (Teruel, Espagne). 1. La vallée de Camarena (Lepidoptera, Papilionoidea et Zygaenidae). Alexanor, 18(3): 147-153.

Tolman, T. \& Lewington, R., 2002. Guía de las Mariposas de España y Europa. Lynx Edicions. Barcelona. 320 pp.

Tormo, J. E., 1983. Algunos ropalóceros de la provincia de Alicante. SHILAP Revista de lepidopterología, 11(43): 225-226

Tormo, J. E., 1985. Más lepidópteros de la provincia de Alicante. SHILAP Revista de lepidopterología, 13(49): 32 .
Torres Sala, J., 1962. Catálogo de la colección entomológica "Torres Sala" de Coleópteros y Lepidópteros de todo el mundo. Vol. II. Institución Alfonso el Magnánimo. Diputación provincial de Valencia. Valencia. 212 pp.

ZAPATER, B. \& Korb, M., 1883. Catálogo de los lepidópteros de la provincia de Teruel, y especialmente de Albarracín y su Sierra. Anales de la Sociedad española de Historia Natural, 12: 273-318.
Recibido, 19-II-2007

Aceptado, 4-V-2007

Publicado, 27-VI-2007 